\title{
The Fate of Certain Organic Acids and Amides in the Rabbit
}

\author{
6. NITROBENZOIC ACIDS AND AMIDES \\ By H. G. BRAY, W. V. THORPE AND P. B. WOOD \\ Department of Physiology, Medical School, University of Birmingham
}

\section{(Received 4 June 1948)}

Studies in vitro (Bray, James, Ryman \& Thorpe, $1948 a$ ) have shown that rabbit-liver extracts are able to hydrolyze all three nitrobenzamides. The para isomer is most readily attacked, the average hydrolysis being $82 \%$; under the same conditions the meta and ortho isomers are hydrolyzed to the extent of 31 and $23 \%$, respectively. It was, therefore, of interest to study the metabolism of these compounds in vivo, comparing them with the corresponding nitrobenzoic acids. The literature contains little information concerning the metabolism of these acids in the rabbit, though there are some acc ounts of investigations upon other animals. As early as 1851 Bertagnini found that $m$-nitrobenzoic acid was excreted as the corresponding hippuric acid by the dog. Quick (1932) included the three nitrobenzoic acids in an extensive study of the glycine and glucuronic acid conjugation of nuclear substituted benzoic acids in the dog and found that the meta and para isomers, but not the ortho, were conjugated with glycine to a considerable extent and that all three were excreted to some extent as ester glucuronides.

Nitrobenzaldehydes and nitrotoluenes are oxidized to the corresponding nitrobenzoic acids in vivo. o-Nitrobenzaldehyde is excreted as o-nitrobenzoic acid in man (Sherwin \& Hynes, 1921), rabbit (Cohn, 1893) and dog (Sieber \& Smirnow, 1887). $m$ - and $p$-Nitrobenzaldehydes give rise to the corresponding nitrobenzoic and hippuric acids in man (Sherwin \& Hynes, 1921) and dog (Sieber \& Smirnow, 1887). Cohn (1893) also found that $m$-nitrobenzaldehyde was converted to some extent to $m$-nitrohippuric acid in the rabbit, though conjugation with glycine did not appear to take place with the para isomer in this animal. Jaffe (1878-9) found that $o$-nitrotoluene was converted in the dog to the corresponding benzyl alcohol and benzoic acid, the latter being excreted unconjugated; $p$-nitrotoluene (Jaffe, 1874) was oxidized to $p$-nitrobenzoic acid which was excreted as its glycine conjugate.

A further change which aromatic nitro acids may undergo in vivo is reduction of the nitro group. Cohn $(1893,1894)$ was the first to observe this, isolating $m$-acetamidobenzoic acid as a metabolite of $m$ nitrobenzaldehyde and $m$-nitrobenzoic acid in the rabbit; he also isolated $p$-acetamidobenzoic acid as a metabolite of $p$-nitrobenzaldehyde. The extent of reduction was greater with the meta aldehyde than with the corresponding acid. Sherwin \& Hynes (1921) did not observe any reduction of nitrobenzaldehydes in man. More recently some results of a study of the reduction of nitrobenzoic acids in the rat, and in vitro by rat and mouse liver and kidney have been reported (Kohl \& Flynn, 1941). These will be referred to later.

In the present study we have investigated the excretion of ether-soluble acid and diazotizable material by rabbits, after the administration of the nitrobenzoic acids and amides, and have also identified their principal metabolites.

\section{METHODS}

Diet and dosing. The rabbits used were does of approx. $3 \mathrm{~kg}$. wt. The diet of rabbit pellets has already been described (Bray, Ryman \& Thorpe, 1947). The compounds were administered by stomach tube, the acids as solutions in $\mathrm{NaHCO}_{3}$ and the amides, which were prepared by the action of $\mathrm{NH}_{3}$ on the corresponding acid chlorides, as suspensions in water. All the acids and amides could be safely administered at a dose level of $0.1 \mathrm{~g} . / \mathrm{kg}$., and in most cases doses of $0.2 \mathrm{~g} . / \mathrm{kg}$. caused no ill effects. Repeated administration of any of the compounds, however, resulted in death. 0 -Nitrobenzamide was the most toxic compound of the series and in some cases the administration of a single dose, even at the lower level, was fatal. Consequently, the number of experiments we were able to make with this compound was limited.

Estimation of ether-soluble acid. The method was that used previously (Bray et al. 1947). The ether-soluble material was titrated directly against $0.05 \mathrm{~N} \mathrm{NaOH}$ with thymol blue as indicator.

Estimation of diazotizable material. The method used was that of Bratton \& Marshall (1939). The standard used for comparison was a solution of the corresponding aminobenzoic acid. The estimation was performed on the urine (a) as collected, (b) after acetylation, (c) after hydrolysis and $(d)$ after reduction. Acetylation was effected by shaking together urine $(10 \mathrm{ml}$.) and acetic anhydride $(1 \mathrm{ml}$.) for $1 \mathrm{~min}$., and allowing the mixture to stand for $30 \mathrm{~min}$. before estimating in the usual way. Control experiments showed that solutions of aminobenzoic acids of equivalent concentration were completely acetylated by this treatment, and it was therefore assumed that any colour produced by the diazotization and coupling of acetylated urine was due to hydroxylamine derivatives (cf. Rosenthal \& Bauer, 1939). Hydrolysis was carried out as in the Bratton 
\& Marshall procedure. Since the amounts of hydroxylamine derivatives detected were very small (see p. 41), any changes they undergo on hydrolysis may be neglected, and the result obtained by estimation of hydrolyzed urine taken as indicating the total extent of reduction in vivo and, in conjunction with the result obtained from hydrolyzed urine, of the degree of acetylation. Reduction was effected by treating the urine (10 ml.) with $\mathrm{HCl}(4 \mathrm{ml}$., $2 \mathrm{~N}$ ) and granulated $\mathrm{Zn}$ (200 mg.) in a boiling water bath for $1 \mathrm{hr}$. Estimation on this solution gave the total excretion of nitro compound, whether reduced, acetylated or unchanged. Reduction by $\mathrm{TiCl}_{3}$ (Eckert, 1943) was found to give less satisfactory results. Control experiments showed that $p$-nitrobenzoic acid and amide were both reduced to the extent of $92 \%$ (average of 5 estimations, range $89-93 \%$ ). This value could not be increased by, e.g. recrystallization of acid, increased reduction time or use of more $\mathrm{Zn}$, and so the necessary correction factor was applied to the calculation of results. The meta isomers were both quantitatively reduced. o-Nitrobenzoic acid was also quantitatively reduced, but it was found that $o$-nitrobenzamide urines on diazotization and coupling gave a bluish red colour which could not be matched against any standard used, so that no quantitative diazo estimations were carried out.
Estimation of reducing material. This was carried out with unhydrolyzed urine by the method already described (Bray, Neale \& Thorpe, 1946).

Estimation of ethereal sulphate. The method of Folin (1905-6) was again used.

\section{RESULTS}

\section{Quantitative studies}

Excretion of ether-soluble acid. The average normal values for individual rabbits lay between 692 and $807 \mathrm{mg} . /$ day (calculated as hippuric acid). The day-to-day variation in output for each rabbit was usually within $\pm 7 \%$ of the mean. Table 1 shows the percentages of doses excreted as ether-soluble acid, calculated in all cases as nitrobenzoic acid. A possible source of error is the fact that the 'extra' ether-soluble acid does not consist solely of nitrobenzoic acid, though this undoubtedly constitutes the major part of it. It can be seen from Table 2 that a portion of the dose of all six compounds studied is excreted as the corresponding aminobenzoic acid, partly free and partly acetylated. Acetamidobenzoic acids are extracted quantitatively under the conditions used here (cf. Bray \& Thorpe, 1948). The

Table 1. Excretion of ether-soluble acid (calculated as nitrobenzoic acid) by rabbits after the administration of nitrobenzoic acids and amides

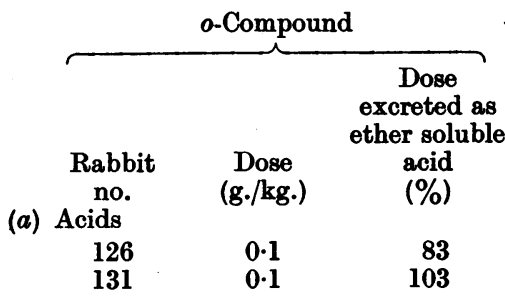

Averages

126

131

$$
\begin{gathered}
0 \cdot 2 \\
0 \cdot 2 \\
0 \cdot 2
\end{gathered}
$$

\begin{tabular}{|c|c|}
\hline . & \\
\hline $\begin{array}{c}\text { Rabbit } \\
\text { no. }\end{array}$ & $\begin{array}{c}\text { Dose } \\
\text { (g./kg.) }\end{array}$ \\
\hline 84 & $\begin{array}{l}0.1 \\
0.1\end{array}$ \\
\hline 109 & $0 \cdot 1$ \\
\hline 126 & 0.1 \\
\hline
\end{tabular}$$
103
$$

93

85

96

83

Averages

88

(b) Amides

126

131

$0 \cdot 1$

$0 \cdot 1$

29

23

26

Averages

126

131
0.2

$0 \cdot 2$

19
10

84
109
126
131

131

84

109

\section{$0 \cdot 2$}

$0 \cdot 2$

$0 \cdot 2$

0.2

$0 \cdot 2$

$\begin{array}{rr}84 & 0 \cdot 1 \\ & 0 \cdot 1 \\ 109 & 0 \cdot 1 \\ & 0 \cdot 1 \\ 131 & 0 \cdot 1\end{array}$

\begin{tabular}{|c|c|c|}
\hline $\begin{array}{c}\text { Rabbit } \\
\text { no. }\end{array}$ & $\begin{array}{c}\text { Dose } \\
\text { (g./kg.) }\end{array}$ & $\begin{array}{c}\text { Dose } \\
\text { excreted as } \\
\text { ether soluble } \\
\text { acid } \\
(\%)\end{array}$ \\
\hline 84 & $\begin{array}{l}0.1 \\
0.1\end{array}$ & $\begin{array}{l}97 \\
96\end{array}$ \\
\hline 109 & $\begin{array}{l}0 \cdot 1 \\
0.1\end{array}$ & $\begin{array}{r}125 \\
99\end{array}$ \\
\hline
\end{tabular}

$p$-Compound

105

$\begin{array}{rl}84 & 0 \cdot 1 \\ & 0 \cdot 1 \\ 109 & 0 \cdot 1 \\ & 0.1\end{array}$


Table 2. Diazotizable material in rabbit urine after administration of nitrobenzoic acids and amides

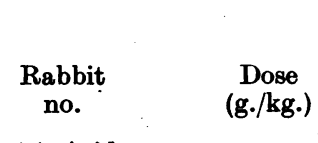

(a) Acid

109
126
131

Averages

126

131

Averages

(a) Acid

84

109

126

Averages

\begin{tabular}{cc}
84 & $0 \cdot 2$ \\
109 & 0.2 \\
131 & $0 \cdot 2$ \\
Averages & \\
\hline
\end{tabular}

(b) Amide

84

109

131

Averages

101

109

Averages

(a) Acid

84

109

Averages

84

109

Averages

(b) Amide 84

109

Averages

$\begin{array}{rl}84 & 0.2 \\ 109 & 0 \cdot 2 \\ & 0 \cdot 2 \\ & 0 \cdot 2\end{array}$

Averages
0.1

0.1

0.1

0.2

0.2

0.2

0.1

0.1

$0 \cdot 1$
$0 \cdot 1$

$0 \cdot 1$

$0 \cdot 2$

$0 \cdot 2$

$0 \cdot 1$

$0 \cdot 1$

$0 \cdot 1$

$0 \cdot 1$

$0 \cdot 1$

$0 \cdot 2$

$0 \cdot 2$

0.2

0.1

$0 \cdot 1$

$0 \cdot 1$

$0 \cdot 1$

0.2

0.2

$0 \cdot 2$
$0 \cdot 2$

$0 \cdot 1$

$0 \cdot 1$

$0 \cdot 1$

0.1

$0 \cdot 2$
$0 \cdot 2$
$0 \cdot 2$
$0 \cdot 2$

Dose excreted as diazotizable material in urine (\%)

\begin{tabular}{|c|c|}
\hline $\begin{array}{c}\text { As } \\
\text { collected }\end{array}$ & $\begin{array}{c}\text { After } \\
\text { acetylatio }\end{array}$ \\
\hline
\end{tabular}

o.Compound

21
18
27
22
26
19
24
23

23

$1.2 \quad 20$

$2 \cdot 6$

1.9

20

24

75

1.920

74

73

$3 \cdot 7 \quad 26$

$4 \cdot 3 \quad 16$

$1.5 \quad 23$

3.2

22

74

81

79

76

$m$-Compound

$1.9 \quad-14 \quad 85$

$\begin{array}{lrr}1.6 & 9 & 85\end{array}$

$\begin{array}{lll}0.7 & 13 & 78\end{array}$

0.4
11 $\quad 81$

$\begin{array}{lrr}1 \cdot 1 & 9 & 90\end{array}$

4.7

$5 \cdot 6$

$1 \cdot 1$

11

84

$3 \cdot 9$

$5 \cdot 1$

$3 \cdot 9$

$4 \cdot 3$

0.9

$0 \cdot 6$

$0 \cdot 6$

8

0.7

12

10

74

78

90

81

$\begin{array}{lll}1.7 & 26 & 73\end{array}$

$\begin{array}{lll}1.7 & 26 & 77\end{array}$

$\begin{array}{lll}0.9 & 27 & 72\end{array}$

$\begin{array}{lll}1 \cdot 1 & 29 & 81\end{array}$

$\begin{array}{lll}1.5 & 24 & 73\end{array}$

$\begin{array}{lll}1.4 & 26 & 75\end{array}$

$\begin{array}{lll}0.7 & 27 & 75\end{array}$

$\begin{array}{lll}0.6 & 24 & 80\end{array}$

$\begin{array}{lll}0.6 & 21 & 79\end{array}$

2.2

0.6

24

78

$p$-Compound

$2 \cdot 2$
$1 \cdot 6$

1.5

$1 \cdot 1$

$1 \cdot 1$

$15 \quad 90$

0.9

96

0.9
0.7

13

$1 \cdot 6$

0.9

86

$1 \cdot 4$

1.0

0.9

1.7

$1 \cdot 2$

0.5

0.5
0.5

0.4

0.5

0.5

9

90

86

100

86

90

91

$2 \cdot 5$

$1 \cdot 4$

$2 \cdot 2$

$1 \cdot 2$

0.8

$1 \cdot 1$

1.7

$2 \cdot 3$

1.2

$\begin{array}{ll}16 & 91 \\ 15 & 97 \\ 13 & 88 \\ 16 & 99 \\ 15 & 94\end{array}$

$\begin{array}{ll}16 & 91 \\ 15 & 97 \\ 13 & 88 \\ 16 & 99 \\ 15 & 94\end{array}$

$\begin{array}{ll}16 & 91 \\ 15 & 97 \\ 13 & 88 \\ 16 & 99 \\ 15 & 94\end{array}$

$1 \cdot 2$

$3 \cdot 0$
$1 \cdot 5$

1.7

0.5

1.0

$1 \cdot 1$

$0 \cdot 6$

0.8

1.9

$14 \quad 101$

94

$\begin{array}{rr}14 & 97 \\ 15 & 102\end{array}$

$15 \quad 99$

15

100 
largest acetyl excretion is from $m$-nitrobenzamide, and even here the error due to calculation of $m$-acetamidobenzoic acid as nitrobenzoic acid would be less than $2 \%$ (low). Only about $90 \%$ of free aminobenzoic acids are extracted under the conditions used (pH 1.5-2.0; $\mathrm{pH} \mathrm{4.0}$ is necessary for complete extraction (Bray, Lake, Neale, Thorpe \& Wood, $1948 b)$ ). The greatest conversion to free aminobenzoic acid occurs in the ortho isomer (22\%): thus the error due to unextracted aminobenzoic acid would be about $2.2 \%$ (low). Calculation of the extracted aminobenzoic acid (19.8\%) as nitrobenzoic acid would give a value $4 \cdot 3 \%$ high, so that the net error due to aminobenzoic. acid would only be of the order of $2 \%$ (high), which is hardly significant, even in this extreme case. There is also the possibility in the meta and para isomers of conjugation with glycine, but qualitative studies, described below, led us to conclude that the amounts of nitrohippuric acid excreted are very small, if indeed such compounds are formed at all. It is probable, therefore, that the results given in Table 1 give a reliable indication of the relative amounts of the amides hydrolyzed, since the conditions used were identical for both acid and amide urines. This is least certain in the case of 0 -nitrobenzamide in view of the more complex nature of its excretion products. As reported later, however, the only material isolated from acidified $o$-nitrobenzamide urine under the conditions used for the estimation of ethersoluble acid appeared to consist of small amounts of unchanged amide and 0 -nitrobenzoic acid. The hydroxylated metabolites appear to be largely conjugated with sulphuric or glucuronic acids, the resulting conjugates being not appreciably soluble in ether.

Excretion of diazotizable material. The results obtained are summarized in Table 2. As already stated, the standards used in the diazo estimations were the corresponding aminobenzoic acids. The interpretation of the results for the meta and para isomers is straightforward since there is no significant difference between the degrees of reduction of the acids and their amides by $\mathrm{Zn}$ and $\mathrm{HCl}$ or between the intensities of the colours developed from them on diazotization and coupling (see Bray et al. 1948b). The results obtained with o-nitrobenzoic acid similarly may be interpreted directly, but no values can be given for its amide, since most of the colours given could not be matched with either an anthranilic acid or an amide standard. This is due to the fact that 0 -nitrobenzamide is hydroxylated to a considerable extent in the rabbit. The only colour which could be matched was that given by acetylated urine. The results corresponded to $1-2 \%$ of the dose.

Our results in general are similar to those obtained by Kohl \& Flynn (1941) using rats. These investigators found that $21 \%$ of $0-, 8 \%$ of $m$ - and $2.5-4.0 \%$ of $p$-nitrobenzoic acid was excreted as unconjugated amino compounds; the percentages of the doses of $m$ - and $p$-nitrobenzoic acids excreted-as acetamido compounds were 22 and 11-20 respectively. By reduction of the urines 72, 63 and 89-94\% of the doses of the $0-, m$-and $p$-acids were accounted for.

Excretion of ethereal sulphate. The only one of the compounds under investigation to cause an increase in the excretion of ethereal sulphate was 0 -nitrobenzamide. In 3 experiments at dose levels of 0.1 and $0.2 \mathrm{~g} . / \mathrm{kg} .48,49$ and $46 \%$ of the doses were excreted conjugated with $\mathrm{H}_{2} \mathrm{SO}_{4}$. The average normal daily excretion of ethereal sulphate by individual rabbits ranged from 24-52 mg. $\mathrm{SO}_{3}$. The day-today variation in output for each rabbit was usually within $\pm 7 \%$ (i.e. approx. $3 \mathrm{mg}$.) of the mean.

Excretion of reducing material. The values obtained cannot be regarded as reliable since $(a)$ the actual increases were very small compared with the variations which occur in the amounts of reducing material normally excreted, and (b) diazo estimations (Table 2) suggest the presence of small amounts of hydroxylamino compounds which would be reducing. Furthermore, there was considerable variation in the values obtained for each compound. The average values for the percentage of the dose excreted as apparent ester glucuronide were: ortho acid $16 \%$ (range 6-25); amide $12 \%$ (range 11-13); meta acid 8\% (range 0-17); amide $4 \%$ (range 2-5); para acid 3\% (range 0-10); amide $8 \%$ (range 0.21). The amounts were too small for isolation. The average normal daily excretion of reducing material ranged from 211 to $270 \mathrm{mg}$. (calculated as glucuronic acid).

Reduction of nitrobenzoic acids and amides by rabbit-liver extracts in vitro. Solutions of the acids and amides (100 mg./ $100 \mathrm{ml}$.) in phosphate buffer $\mathrm{pH} 7.4$ were incubated at $37^{\circ}$ with extracts of rabbit liver (4 ml. extract/20 ml. solution) prepared as described previously (Bray et al. 1948a). After $24 \mathrm{hr}$., samples of the digest $(2 \mathrm{ml}$.) were withdrawn, deproteinized with $10 \%$ trichloroacetic acid $(8 \mathrm{ml}$.) and diazotizable material estimated in the filtrate by the method of Bratton \& Marshall (1939), using aminobenzoic acid standards. Table 3 shows the percentages of the compounds converted into diazotizable material under these conditions in $24 \mathrm{hr}$. The results obtained by Kohl \& Flynn (1941) for the reduction of the acids by rat liver $i n$ vitro are also shown. The results obtained with o-nitrobenzamide cannot be interpreted fully since it is not known whether the reduction product is 0 -aminobenzoic acid or its amide, the extracts used being capable of hydrolyzing the amide (e.g. to an extent of $25 \%$ in the second experiment: see also Bray et al. $1948 a$ ). If the amino amide is formed the results are low, since that compound on diazotization and coupling gives only $58 \%$ of the colour given by a solution of anthranilic acid of equivalent strength (Bray et al. 1948b).

Table 3. Reduction of nitrobenzoic acids and amides by rabbit-liver extracts in vitro at $\mathrm{pH} 7 \cdot 4$

Percentage reduction in $24 \mathrm{hr}$.

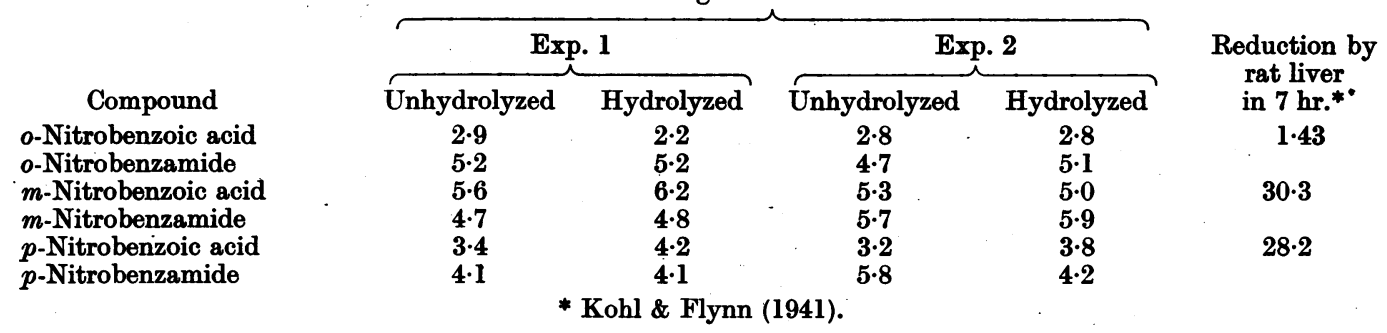


Hydrolysis of the digests in most cases caused a slight increase (up to $0.8 \%$ ) in the amount of diazotizable material present. We were not able to determine whether this was due to acetylation as the change is within the limits of experimental error. Klein \& Harris (1938) found that acetylation of sulphanilamide occurred only with liver slices and not in brei. We ourselves (unpublished results) have found that the liver extracts used brought about the deacetylation of acetanilide, $o-, m$ - and $p$-acetotoluidides, $m$-acetamidobenzoic acid and $p$-hydroxyacetanilide (cf. Michel, Bernheim \& Bernheim, 1937).

\section{Qualitative experiments}

These were carried out in order to determine the nature of the main excretion products of the 6 compounds being studied. Continuous ether extraction of the acidified nitrobenzoic acid urines resulted in the isolation in all 3 cases of the unchanged acid in considerable amounts. They were recrystallized from water and their identity confirmed by comparison with authentic specimens. The mother liquors in every case gave a positive diazo reaction, but the compounds responsible were not isolated.

From $p$-nitrobenzamide urines, $p$-nitrobenzoic acid was isolated in yields similar to those obtained from the acid, which is in accordance with the quantitative finding that the carbamyl group in $p$-nitrobenzamide is virtually completely hydrolyzed in the rabbit.

Ether extraction of acidified $m$-nitrobenzamide urine led to the isolation and characterization of $m$-nitrobenzoic acid. Extraction of the urine as collected ( $\mathrm{pH} 8$ ) gave $m$-acetamidobenzamide, m.p. $219^{\circ}$, mixed m.p. with an authentic sample (m.p. $220^{\circ}$ ), $219^{\circ}$. Yield, $100 \mathrm{mg}$. from $2.5 \mathrm{~g}$. amide administered. This provides direct evidence that the carbamyl group in $m$-nitrobenzamide is not completely hydrolyzed in the rabbit, and that the reduction product is the corresponding amino compound:

All attempts to isolate glycine conjugates of $m$ - and $p$ nitrobenzoic acids were unsuccessful: similar results were obtained from experiments in which glycine $(0.2 \mathrm{~g}$.) was administered along with the acids $(0.4 \mathrm{~g}$.). It thus appears probable that $m$ - and $p$-nitrohippuric acids are not formed as metabolites of the nitrobenzoic acids in the rabbit. No evidence for the formation of azoxy, azo or hydrazo compounds was obtained.

As already mentioned, ether extraction of $o$-nitrobenzamide urine as collected gave small amounts of the amide itself, and extraction of acidified urine gave very small amounts of $o$-nitrobenzoic acid. The isolation of metabolites from hydrolyzed $o$-nitrobenzamide urine was difficult on account of the low dose level which had to be used. A typical experiment was as follows: the $24 \mathrm{hr}$. urine (4 l.) of 12 rabbits which had received o-nitrobenzamide $(0.4 \mathrm{~g}$. each) was hydrolyzed by boiling for $30 \mathrm{~min}$. with conc. $\mathrm{HCl}$ $(0.2$ vol.), adjusted to $\mathrm{pH} 5$ and continuously extracted with ether for $96 \mathrm{hr}$. The ether layer showed an intense blue fluorescence which persisted throughout this period. The ether-soluble material consisted of a dark brown syrup containing some solid matter (extract A). The urine was reacidified as before, boiled for $1 \mathrm{hr}$. and continuously extracted with ether for $48 \mathrm{hr}$. to yield extract $B$, a brown syrup. The $\mathrm{pH}$ of the urine was then adjusted to 5 and extraction with ether continued for a further $96 \mathrm{hr}$.; the ether layer again showed a blue fluorescence. In this way extract C was obtained.
Extract $A$. On the addition of a little ethanol the syrup dissolved and crystalline material $(50 \mathrm{mg}$.) remained which did not melt below $300^{\circ}$ and gave no coloration with $\mathrm{FeCl}_{3}$ and a negative diazo reaction. Boiling with conc. $\mathrm{HCl}$ did not liberate a diazotizable amino group, but gave a crystalline compound which appeared to be a hydrochloride (D). A solution of the crystals in water slowly deposited the free base as needles which had no m.p. but decomposed with volatilization at $360^{\circ}$. Analysis of the hydrochloride gave $\mathrm{C}, 46.3 ; \mathrm{H}, 4.9 ; \mathrm{N}, 11 \cdot 7 ; \mathrm{Cl}, 15 \cdot 1 \%$. The hydrochloride did not give a diazo reaction after reduction with $\mathrm{Zn}$ and $\mathrm{HCl}$. Its properties were not compatible with those which would be expected from an azoxy, azo or hydrazo compound.

Addition of more ethanol to the syrup gave a further amount of solid material (50 mg.) which decomposed at $220-240^{\circ}$ and gave an intense purple-brown coloration and precipitate with $\mathrm{FeCl}_{3}$, a positive diazo reaction (a blueviolet colour developing slowly), a positive indophenol reaction and an intense blue fluorescence in ethereal solution. On acetylation it gave a crystalline compound, m.p. 235$236^{\circ}$. By comparison with authentic specimens it was shown that the compound isolated was 5-hydroxyanthranilic acid (cf. Bray et al. 1948b). The syrup which remained after the removal of the solid material gave a positive diazo reaction (reddish purple) and a purple-brown coloration with $\mathrm{FeCl}_{3}$. It was extracted with boiling water and from the aqueous extract needle-like crystals, m.p. $174^{\circ}$, were obtained (100 mg.). These were shown to be o-nitrobenzamide, since they did not depress the m.p. $\left(174^{\circ}\right)$ of an authentic sample. The colour reactions of the syrup remaining were unchanged. Unsuccessful attempts were made to isolate the metabolites present (probably, judging from the diazo colours, anthranilic and 5-hydroxyanthranilic acids or their amides) by treatment with water or organic solvents and by acetylation.

Extract $B$. The only compounds identified in this fraction were $o$-nitrobenzoic acid ( $150 \mathrm{mg}$.) and benzoic acid ( $200 \mathrm{mg}$.), the latter presumably derived from hippuric acid.

Extract $C$. This contained some solid material which could be separated from the syrup present by treatment with ethanol; it was shown to be 5-hydroxyanthranilic acid. The ethanolic solution gave a brownish colour with $\mathrm{FeCl}_{3}$ and a yellow coloration with $\mathrm{HNO}_{2}$ which might have been due to the presence of an 0 -aminophenol derivative such as 3-hydroxyanthranilic acid (cf. Bray et al. 1948b), but the amount was too small to permit of its identification.

In another experiment a further product was obtained in addition to those already described. This was an amorphous powder which did not melt below $300^{\circ}$ and gave no coloration with $\mathrm{FeCl}_{3}$ and a negative diazo reaction. On boiling with conc. $\mathrm{HCl}$ for $3 \mathrm{hr}$. and evaporation of the resultant solution a crystalline compound was obtained which appeared to be identical with the hydrochloride $D$ from extract A. Further evaporation of the mother liquor gave prisms giving positive diazo, $\mathrm{FeCl}_{3}$ and indophenol reactions. These were identified as 5-hydroxyanthranilic acid hydrochloride. Found: $\mathrm{N}, 7 \cdot 6$. Calc. for $\mathrm{C}_{7} \mathrm{H}_{8} \mathrm{NO}_{3} \mathrm{Cl}: \mathrm{N}$, $7 \cdot 4 \%$.

\section{DISCUSSION}

Table 4 summarizes the analytical results obtained. In view of the unreliability of the values for ester glucuronide (q.v.) ether-soluble acid excretion only has been given for the degree of hydrolysis of the 

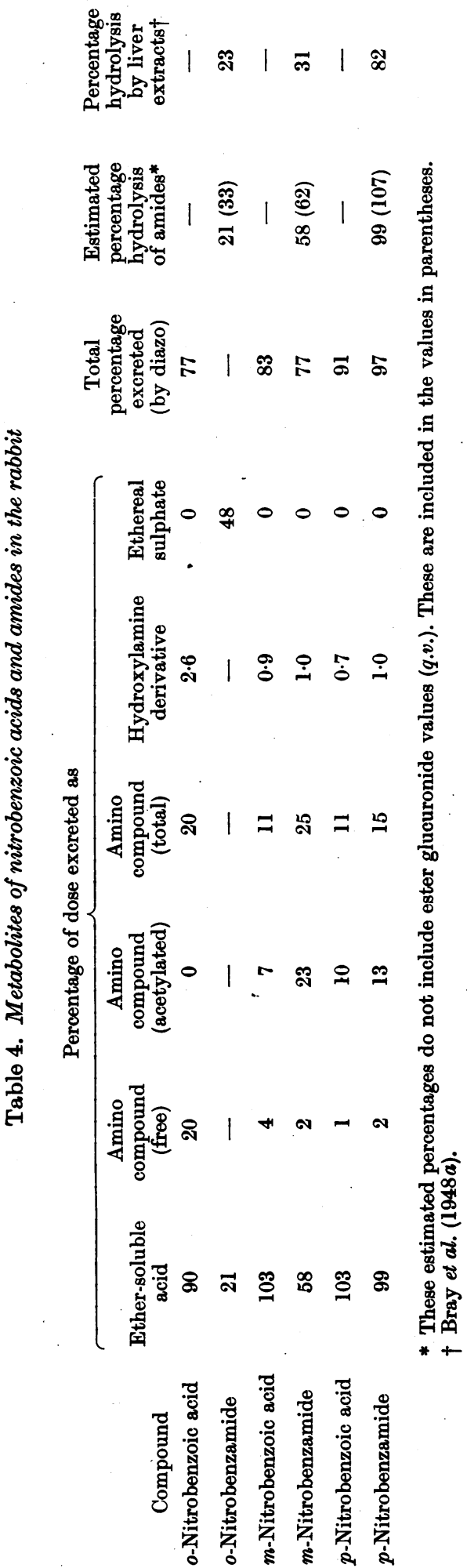

amides in the rabbit, so that these estimates may be low. The figures in parentheses give the degree assuming all the reducing value to be due to ester glucuronide and are almost certainly too high. The results are of the same order as those obtained using rabbit-liver extracts (Bray et al. 1948a). This agreoment has been found in all the aromatic amides so far studied, as shown in Table 5, if allowance is

Table 5. Hydrolysis of nuclear substituted benzamides in the rabbit and by extracts of rabbit liver in vitro

$\begin{array}{cc}\text { Percentage hydrolysis } \\ \begin{array}{c}\text { By liver } \\ \text { extract (6) } \\ \text { In intact }\end{array} \\ \text { animal } & \begin{array}{c}\text { (at } \\ \text { equilibrium) }\end{array} \\ 100(1) & 45 \\ 99(2) & 82 \\ 58(2) & 31 \\ 21(2) & 23 \\ 19(3) & 13 \\ 10(3) & 7 \\ 33-12\left(3^{*}\right) & 9 \\ 4(4) & 6 \\ 11(5) & 1 \\ 6(5) & 0\end{array}$

\section{Benzamide \\ $p$-Nitrobenzamide $m$-Nitrobenzamide $o$-Nitrobenzamide $p$-Aminobenzamide $m$-Aminobenzamide $o$-Aminobenzamide $p$-Hydroxybenzamide $m$-Hydroxybenzamide o-Hydroxybenzamide}

* An average is not given here owing to the wide difference in response to dose level.
(1) Bray et al. (1946).
(2) Present paper.
(4) Bray et al. (1947).
(3) Bray et al. (1948b).
Bray et al. (1948c).
(6) Bray et al. (1948a).

made for the essentially dynamic conditions which prevail in the living cell and which, in general, enable reactions to proceed further towards com. pletion than under static conditions in vitro. This agreement has not been observed with the aliphatic amides studied, viz. phenylacetamide, acetamide, propionamide, which are hydrolyzed to a markedly greater extent in vivo than in vitro. There is, however, a considerable time lag in the excretion of these compounds, and it seems possible that their increased time in the body may give the enzymes responsible a better opportunity to bring about hydrolysis. This problem is still under investigation.

The isolation of 5-hydroxyanthranilic acid from hydrolyzed $o$-nitrobenzamide urine suggests that reduction of the nitro group precedes hydroxylation, since this compound was the principal hydroxyla. tion product isolated from hydrolyzed 0 -aminobenzamide urine (Bray et al. 1948b). Indirect support is provided by our failure to detect a nitrohydroxybenzoic acid and by the colour reactions which suggested the presence of 3-hydroxyanthranilic acid. On purely chemical grounds the compound to be expected if hydroxylation preceded reduction would be 4-hydroxyanthranilic acid. The extent of conjugation with sulphate is, however, greater with $o$-nitrobenzamide $(48 \%)$ than with $o$ aminobenzamide (about $30 \%$ ). It is unfortunate 
that it was not possible to obtain a reliable estimate of the amino compounds formed from o-nitrobenzamide. The attempts at diazo estimations suggested the presence of hydroxylamino compounds in very small amounts, although no compounds which might have been formed through hydroxylamino compounds, ө.g. azoxy, azo, or hydrazo compounds, could be detected. The available evidence, therefore, suggests that the sequence of reactions is
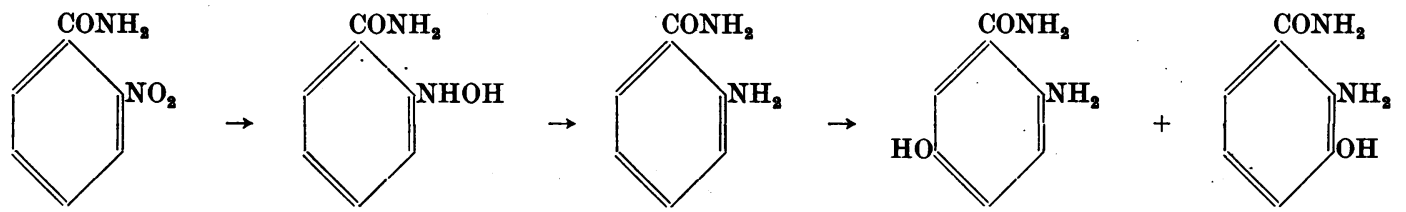

Whilst the absence of sulphate conjugation with 0 -nitro- and $o$-amino-benzoic acids suggests that reduction and hydroxylation precede hydrolysis of the carbamyl group, there is no clear evidence as to whether the reduced compounds were excreted in the form of acids or amides. Very small amounts of o-nitrobenzoic acid were isolated from unhydrolyzed urines, but all the reduction products were obtained from hydrolyzed urines. The fact that the extent of sulphate conjugation was greater than the estimated percentage hydrolysis of the amide does, however, suggest that some hydroxyanthranilamide is not hydrolyzed in vivo.

The isolation of $m$-acetamidobenzamide from $m$ nitrobenzamide urine and the absence of sulphate conjugation lends support to the view that the hydroxylated aminobenzoic acids or amides are produced by hydroxylation of the aminobenzoic acid or amide formed by reduction of the hydroxylamino compounds, and not by rearrangement of the hydroxylamine to an aminophenol.

\section{SUMMARY}

1. A study has been made of the metabolism of $o-, m$ - and $p$-nitrobenzoic acids and amides in the rabbit.

2. The acids are excreted mainly unchanged, but a proportion (11-21\%) is reduced to the corre. sponding aminobenzoic acids. Acetylation then occurs in the $m$ - and $p$-isomers.
3. The amides are hydrolyzed to the corresponding acids : in the case of $p$-nitrobenzamide the hydrolysis is virtually complete, $m$-nitrobenzamide is hydrolyzed to an extent of at least $58 \%$ and $o$ nitrobenzamide at least $21 \%$. Reduction (15-25\%) and acetylation occur as with the acids.

4. 0 -Nitrobenzamide is the only compound of the six to increase excretion of ethereal sulphate, $48 \%$ of the dose being eliminated in this form. The principal hydroxylation product is 5-hydroxyanthranilic acid or amide.

5. Glycine conjugation of nitrobenzoic acids could not be detected in the rabbit.

6. The reduction of nitrobenzoic acids and amides by rabbit-liver extracts has been studied.

We have to thank Dr Sybil P. James for her co-operation in the enzyme studies. Some preliminary experiments for this investigation were carried out by Miss I. M. Raffan. We are indebted to the Royal Society for a Government Grant which defrayed part of the cost of this work. The microanalyses were carried out by Drs Weiler and Strauss, Oxford.

\section{REFERENCES}

Bertagnini, C. (1851). Liebigs Ann. 78, 100.

Bratton, A. C. \& Marshall, E. K. Jr. (1939). J. biol. Chem. 128, 537.

Bray, H. G., James, S. P., Ryman, B. E. \& Thorpe, W. V. (1948a). Biochem. J. 42, 274.

Bray, H. G., Lake, H. J., Neale, F. C., Thorpe, W. V. \& Wood, P. B. (1948b). Biochem. J. 42, 434.

Bray, H..G., Neale, F. C. \& Thorpe, W. V. (1946). Biochem. J. 40, 134.

Bray, H. G., Ryman, B. E. \& Thorpe, W. V. (1947). Biochem. J. 41, 212.

Bray, .H. G., Ryman, B. E. \& Thorpe, W. V. (1948c). Biochem. J. 48, 561.

Bray, H. G. \& Thorpe, W. V. (1948). Biochem. J. 43, 211. Cohn, R. (1893). Hoppe-Seyl. Z. 17, 274.

Cohn, R. (1894). Hoppe-Seyl. Z. 18, 133.
Eckert, H. W. (1943). J. biol. Chem. 148, 197.

Folin, O. (1905-6). J. biol. Chem. 1, 131.

Jaffe, M. (1874). Ber. dtsch. chem. Ges. 7, 1673.

Jaffe, M. (1878-9). Hoppe-Seyl. Z. 2, 47.

Klein, J. R. \& Harris J. S. (1938). J. biol. Chem. 124, 613.

Kohl, M. F. F. \& Flynn, L. M. (1941). Proc. Soc. exp. Biol., N.Y., 47, 470.

Michel, H. O., Bernheim, F. \& Bernheim, M. L. C. (1937). J. Pharmacol. 61, 321.

Quick, A. J. (1932). J. biol. Chem. 86, 83.

Rosenthal, S. M. \& Bauer, H. (1939). Publ. Hlth Rep., Wash., 54, 1880.

Sherwin, C. P. \& Hynes, W. A. (1921). J. biol. Chem. 47, 297.

Sieber, N. \& Smirnow, A. (1887). Mh. Chem. 8, 88. 